\title{
Parâmetros da secagem da banana pacovan e caracterização físico-química da farinha de banana verde
}

\author{
Parameters of drying banana pacovan and physicochemical characterization of \\ green banana flour
}

\author{
Vanusia Cavalcanti França Pires, Flávio Luiz Honorato Silva, Rayane Maria Silva Souza
}

RESUMO - O Nordeste do Brasil é responsável pela maior produção de bananas do país, com cerca de 2,862 milhões de ton. em 2012, entretanto, as altas temperaturas da região são responsáveis por expressivas perdas deste fruto in natura. A banana pode ser processada no estágio de maturação verde e submetida a técnicas de secagem visando a obtenção de produtos com maior vida de prateleira. Este trabalho apresenta os parâmetros cinéticos envolvidos na secagem convectiva da banana Pacovan verde e a obtenção do produto denominado farinha de banana verde (FBV). Foi realizado um planejamento fatorial completo $\left(2^{2}\right)$ com número de experimentos de $2^{\mathrm{n}}+3$, resultando em sete tratamentos. As variáveis reais foram temperatura $\left(50 ; 60\right.$ e $\left.70^{\circ} \mathrm{C}\right)$ e espessura $(5,0 ; 7,5$ e $10,0 \mathrm{~mm})$ e para análise dos resultados, foi utilizado a metodologia da superfície de resposta através do software Statistic for Windows versão 5.0 . Foram aplicados os modelos de Page e de Henderson \& Pabis para os parâmetros cinéticos da secagem. Foram determinados os parâmetros $\mathrm{pH}$, acidez titulável, sólidos solúveis, umidade, proteína, lipídios, fibra bruta e cinzas, na polpa da banana in natura e na farinha de banana verde. Os modelos foram bem representativos para cinco dos sete tratamentos. As respostas (teor de água final e tempo de secagem) foram estatisticamente significativas ao nível de $95 \%$ de confiança. Para espessura fixada em 5,0 mm e temperatura a $70^{\circ} \mathrm{C}$ obtém-se os menores tempos de equilíbrio na secagem. A farinha de banana verde apresentou textura fina, coloração bege claro, insípida e inodora.

PALAVRAS-CHAVE: secagem convectiva; cinética de secagem; planejamento experimental; modelos estatísticos.

SUMMARY - The Northeast of Brazil is responsible for most banana production in the country, with about 2.862 million tons. in 2012, however, the high temperatures in the region are responsible for significant losses this fruit in nature. The banana can be processed at green maturity stage and subjected to drying techniques in order to obtain products with longer shelf life. This paper presents the kinetic parameters involved in convective drying of banana Pacovan green and getting product called green banana flour (FBV). We conducted a complete factorial planning $\left(2^{2}\right)$ number of experiments with $2^{n}+3$, resulting in seven treatments. The real variables were temperature $\left(50,60\right.$ and $\left.70^{0} \mathrm{C}\right)$ and thickness $(5.0,7.5$ and $10.0 \mathrm{~mm})$ and to analyze the results, we used the response surface methodology through software Statistic for Windows version 5.0. We applied the models Page and Henderson \& Pabis kinetic parameters for drying. Parameters were $\mathrm{pH}$, titratable acidity, soluble solids, moisture, protein, fat, crude fiber and ash, the pulp of banana and in nature green banana flour. The models were well representative for five of the seven treatments. Responses (final water content and drying time) were statistically significant at $95 \%$ confidence. For fixed at $5.0 \mathrm{~mm}$ thickness and temperature of $70{ }^{\circ} \mathrm{C}$ is obtained under the equilibration times for drying. The green banana flour had fine texture, color beige, tasteless and odorless.

KEY-WORDS: convective drying, drying kinetics, experimental planning, statistical models. 


\section{INTRODUÇ̃̃O}

O Brasil é o quinto maior produtor mundial de banana, com 7,329 milhões de toneladas, atrás do Equador, Filipinas, China e Índia. A bananeira, no Brasil, é cultivada em praticamente todos os Estados, destacandose: São Paulo e Bahia com produção superior a 1 mil ton, cada um. A região Nordeste é responsável pela maior produção de bananas, com cerca de 2,862 milhões de ton. A produção da Paraíba em 2011 foi de 202.791 ton (IBGE, 2011).

A mesorregião agreste é onde está concentrada a maior área cultivada da Paraíba, ocupando mais de 10.000 hectares. A cultivar "pacovan" ocupa cerca de 95\%, sendo o restante distribuído entre as cultivares "prata-comum", comprida, "maçã", nanica e nanicão. 'Pacovan', uma cultivar do grupo genômico AAB, que é uma mutação da banana 'Prata', tem superado quase em 100\% a produtividade da 'Prata' ( GARRUTI et al., 2012).

As altas temperaturas da região Nordeste são responsáveis por expressivas perdas da banana in natura. Este fruto é altamente perecível e extremamente sensível a danos mecânicos e ao etileno, razão pela qual sua comercialização deve ser rápida para que chegue ao seu destino em boas condições. No campo as bananeiras são suscetíveis ao fungo Mycosphaerella fijiensis Morelet, causador do Mal da Sigatoka Negra, doença que pode causar perdas de até $100 \%$ da produção (GARRUTI et al., 2012).

A banana pode ser processada em diferentes estágios de maturação e uma das opções é submetê-la a processos de secagem ainda verde e o produto obtido, após trituração é chamado farinha de banana verde (FBV). Diversas são as técnicas de secagem que podem ser usadas na desidratação de alimentos, entretanto a secagem convectiva (em leito fixo ou móvel) é uma das mais recomendadas para a banana verde. A diminuição da atividade de água $\left(\mathrm{a}_{\mathrm{w}}\right)$ favorece o transporte $\mathrm{e}$ a manipulação do produto, além de prolongar sua vida de prateleira. Vários modelos matemáticos são utilizados para a representação do comportamento da secagem de produtos agrícolas, entre eles os de Page (1949) e de Henderson e Pabis (1961), são modelos empíricos mais utilizados para a representação da secagem de produtos agrícolas. Dois fenômenos ocorrem simultaneamente quando um sólido úmido é submetido a secagem: transferência de energia (calor) do ambiente para evaporar a umidade superficial e esta transferência depende das condições de temperatura, umidade, fluxo e direção de ar, além da área de exposição do sólido e pressão; transferência de massa (umidade), do interior para a superfície do material e sua subsequente evaporação, isto ocorrerá em função da natureza física do sólido, temperatura e do conteúdo de umidade (SANTOS et al., 2010).

A transformação de bananas verdes em farinha é de grande interesse devido à disponibilidade da matéria- prima durante todo o ano nas regiões produtoras. A industrialização deste produto minimiza as perdas póscolheita e agrega valor econômico ao seu cultivo. A farinha de banana verde (FBV) é um produto que apresenta alto teor de amido e baixo teor de açúcares, podendo ser consumida pura ou incorporada a alimentos. As cultivares de banana mais estudadas para a produção da FBV são a prata, nanicão e terra (SOUZA e LEÃO, 2012; SANTOS et al., 2010; RAMOS et al., 2009; SILVA et al., 2009).

Este trabalho definiu os parâmetros da tecnologia de secagem convectiva para a banana Pacovan, no estádio de maturação verde, e a caracterização físico-química da polpa da banana in natura e da farinha de banana verde (FBV) obtida.

\section{MATERIAL E MÉTODOS}

\section{Matéria-prima}

A matéria-prima utilizada foi a banana Pacovan (Musa sapientum), adquirida no comércio local de frutas do município de Campina Grande (PB), no estádio de maturação verde, determinado pela coloração da casca, variando entre totalmente verde e verde com traços amarelos. As bananas foram transportadas até o Laboratório de Análises de Alimentos do Núcleo de Pesquisa e Extensão em Alimentos (NUPEA), no Centro de Ciências e Tecnologia da Universidade Estadual da Paraíba, Campina Grande (PB) onde foram selecionadas, separados do engaço manualmente com o auxílio de uma faca em inox. Os frutos passaram por um processo de lavagem em água corrente e detergente neutro, sendo eliminadas as sujidades da superfície, sanitizadas por imersão em solução de hipoclorito de sódio na concentração $150 \mathrm{ppm}$, retiradas as cascas com faca de aço inoxidável, a polpa foi cortada, separadamente, em rodelas com diferentes espessuras. As fatias foram submetidas a tratamento antioxidante em solução de ácido cítrico e ácido ascórbico nas concentrações de $0,1 \%$, cada, por um período de 30 minutos, sendo em seguida escorridas e submetidas a branqueamento por cerca de 3 minutos no vapor de água. As rodelas de banana foram então dispostas em bandejas de telas e colocadas em estufa com circulação de ar para o processo de secagem.

\section{Planejamento experimental para secagem da banana verde}

Para o processo de desidratação da banana Pacovan verde, foi utilizada uma estufa com circulação de ar, onde se definiu a temperatura do ar de secagem e a espessura do corte da banana verde, que dependem do tempo, como as variáveis de entrada do processo de secagem, estudando-as em dois níveis, codificados como $1 \mathrm{e}+1$. Na Tabela 1 encontram-se os valores reais e codificados para o planejamento fatorial. 
Tabela 1. Valores reais e níveis dos fatores do planejamento fatorial completo $\left(2^{2}\right)$

\begin{tabular}{c|c|c|c}
\hline \multirow{2}{*}{ Variáveis } & \multicolumn{3}{c}{} \\
& \multicolumn{3}{c}{ Níveis } \\
\hline Temperatura $\left({ }^{\circ} \mathrm{C}\right)$ & -1 & 0 & +1 \\
\hline Espessura $(\mathrm{mm})$ & 50 & 60 & 70 \\
\hline
\end{tabular}

$\mathrm{O}$ número de experimentos foi $2^{\mathrm{n}}+3$, onde " $\mathrm{n}$ " corresponde ao número de variáveis e o "número três" representa as três repetições no ponto central. A Tabela 2

Tabela 2. Matriz do planejamento dos experimentos

\begin{tabular}{ccccc}
\hline \multirow{2}{*}{ Ensaios } & \multicolumn{2}{c}{ Temperatura $(\mathrm{T})$} & \multicolumn{2}{c}{ Espessura (E) } \\
\cline { 2 - 5 } & Codificada & Real $\left({ }^{\circ} \mathrm{C}\right)$ & Codificada & Real (mm) \\
\hline 1 & - & 50 & - & 5,0 \\
\hline 2 & + & 70 & - & 5,0 \\
\hline 3 & - & 50 & + & 10,0 \\
\hline 4 & + & 70 & 0 & 7,0 \\
\hline 5 & 0 & 60 & 0 & 7,5 \\
\hline 6 & 0 & 60 & 0 & 7,5 \\
\hline
\end{tabular}

As respostas avaliadas estatisticamente foram o teor de água de equilíbrio, base seca e o tempo de equilíbrio, em horas. Para a análise dos resultados, foi utilizado a metodologia da superfície de resposta através do software Statistic for Windows versão 5.0 (1995). A Figura 1 mostra o fluxograma de processamento para os ensaios propostos. 


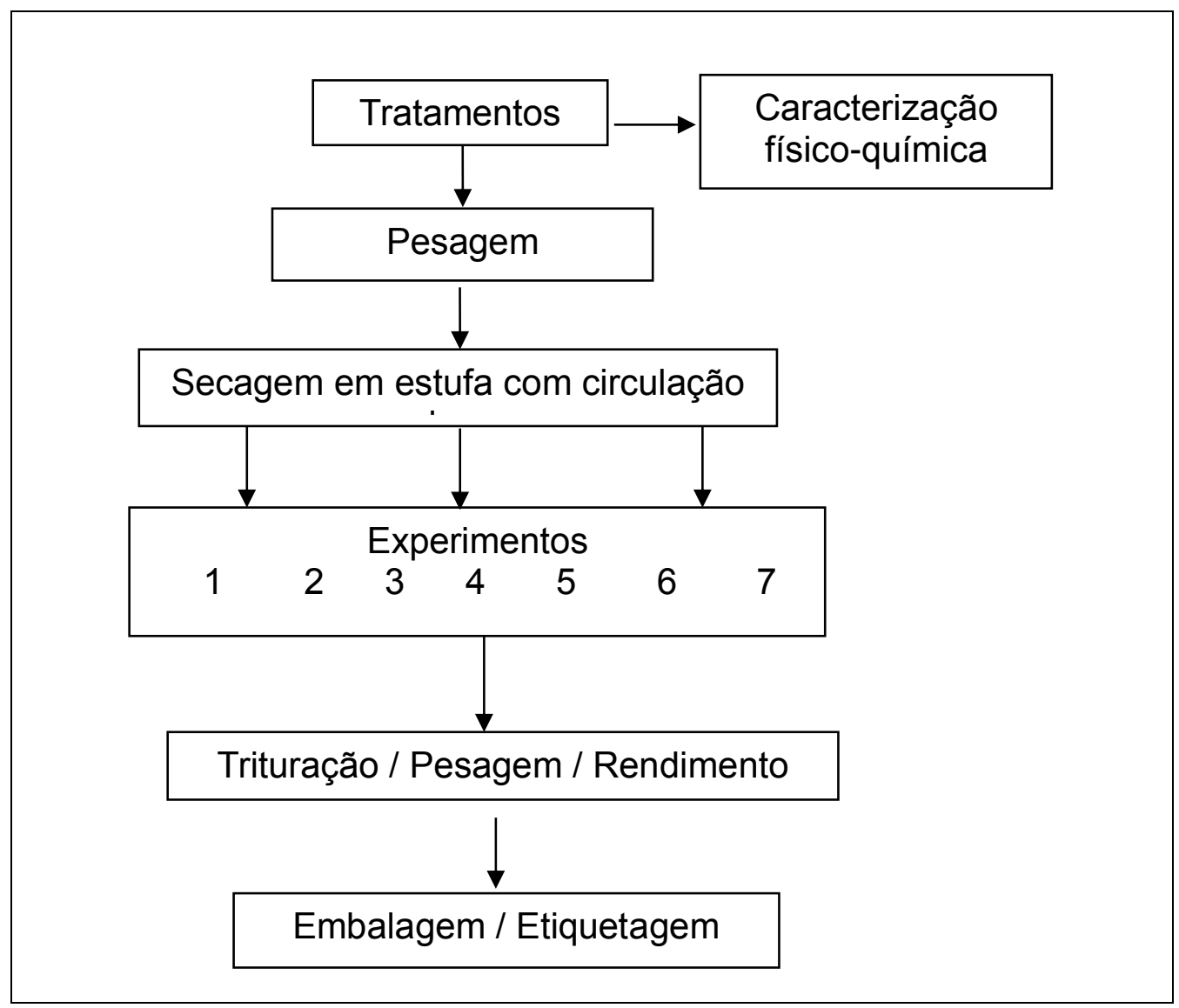

Figura 1. Fluxograma do processo para a produção da FBV

Os parâmetros cinéticos da secagem da banana verde Pacovan para os modelos de Page e de Henderson \&

\section{Parâmetros cinéticos da secagem} Pabis estão apresentados na Tabela 3.

Tabela 3. Parâmetros de ajustes e coeficiente de determinação $\left(\mathrm{R}^{2}\right)$ dos modelos de secagem

\begin{tabular}{|c|c|c|c|c|c|c|c|}
\hline \multirow{2}{*}{ Modelos } & \multirow{2}{*}{$\begin{array}{c}\mathrm{T} \\
\left({ }^{\circ} \mathrm{C}\right)\end{array}$} & \multirow{2}{*}{$\begin{array}{c}\mathrm{E} \\
(\mathrm{mm})\end{array}$} & \multicolumn{3}{|c|}{ Parâmetros } & \multirow{2}{*}{$\mathrm{R}^{2}$} & \multirow{2}{*}{ DQM } \\
\hline & & & $\mathrm{K}$ & $\mathrm{a}$ & $\mathrm{N}$ & & \\
\hline \multirow{7}{*}{ Page } & 50 & 5,0 & 0,0056 & - & 1,0599 & 0,9998 & 0,05191 \\
\hline & 50 & 10,0 & 0,0027 & - & 1,1758 & 0,8998 & 0,44408 \\
\hline & 70 & 5,0 & 0,0095 & - & 1,0549 & 0,9988 & 0,07241 \\
\hline & 70 & 10,0 & 0,0115 & - & 1,1009 & 0,5988 & 0,65778 \\
\hline & 60 & 7,5 & 0,0040 & - & 1,2132 & 0,9562 & 0,28035 \\
\hline & 60 & 7,5 & 0,0039 & - & 1,1350 & 0,9956 & 0,14698 \\
\hline & 60 & 7,5 & 0,0178 & - & 0,8595 & 0,9982 & 0,0822 \\
\hline Henderson & 50 & 5,0 & 0,0076 & 1,0118 & - & 0,9996 & 0,0583 \\
\hline
\end{tabular}




\begin{tabular}{cccccccc}
\hline \multirow{2}{*}{\begin{tabular}{c} 
Pabis \\
\cline { 2 - 7 }
\end{tabular}} & 50 & 10,0 & 0,0070 & 1,0270 & - & 0,8984 & 0,43996 \\
\cline { 2 - 7 } & 70 & 5,0 & 0,0121 & 1,0021 & - & 0,9986 & 0,06983 \\
\hline & 70 & 10,0 & 0,0176 & 0,9952 & - & 0,5982 & 0,65511 \\
\hline 60 & 7,5 & 0,0113 & 1,0426 & - & 0,9543 & 0,27919 \\
\hline 60 & 7,5 & 0,0078 & 1,0292 & - & 0,9948 & 0,15073 \\
\hline
\end{tabular}

Em análise a estes resultados verifica-se que os experimentos $2\left(\mathrm{~T}=50^{\circ} \mathrm{C}\right.$ e $\left.\mathrm{E}=10,0 \mathrm{~mm}\right)$ e $4\left(\mathrm{~T}=70^{\circ} \mathrm{C} \mathrm{e}\right.$ $\mathrm{E}=10,0 \mathrm{~mm}$ ) não representam bem o processo de secagem para os dois modelos estudados, visto que estes apresentam valores baixos para $\mathrm{R}^{2}$ e altos para o DQM. Tal fato está relacionado à espessura, que como nestes experimentos são as maiores podem provocar contração do material ao longo da secagem (o encolhimento é mais perceptível) ou formação de uma película na superfície do material parcialmente seco, o que pode ter feito com que o modelo não se ajustasse fielmente aos dados experimentais, pois o modelo não leva em conta o encolhimento.

Para os demais experimentos, verifica-se que os modelos representam bem o processo de secagem, pois apresentam valores altos para $\mathrm{R}^{2}$ e baixos para o DQM.

\section{Análises físico-químicas da polpa e da farinha da banana verde}

As análises foram conduzidas conforme Instituto Adolfo Lutz (2008) sendo determinados os seguintes parâmetros: pH, acidez titulável, sólidos solúveis, umidade, proteína, lipídios, fibra bruta e resíduos minerais fixo (cinzas). $O$ teor de carboidratos foi obtido por diferença percentual.

\section{RESULTADOS E DISCUSSÃO}

\section{Curvas de secagem da banana verde}

As curvas de secagem foram representadas na forma adimensional (RU) em função do tempo de secagem (min). As diferenças entre as curvas de secagem são causadas pelas diferenças nas temperaturas e nas espessuras das fatias de bananas conforme as condições experimentais. Os experimentos não foram até o período de taxa constante, portanto foi realizada uma extrapolação visual até a taxa zero. $\mathrm{O}$ comportamento cinético para as diferentes temperaturas $\left(50\right.$ e $\left.70^{\circ} \mathrm{C}\right)$ e espessuras $(5,0$ e $10,0 \mathrm{~mm}$ ) durante a secagem das bananas verdes, com a evolução de umidade na base seca em função do tempo de secagem, encontram-se representados nas figuras a seguir.
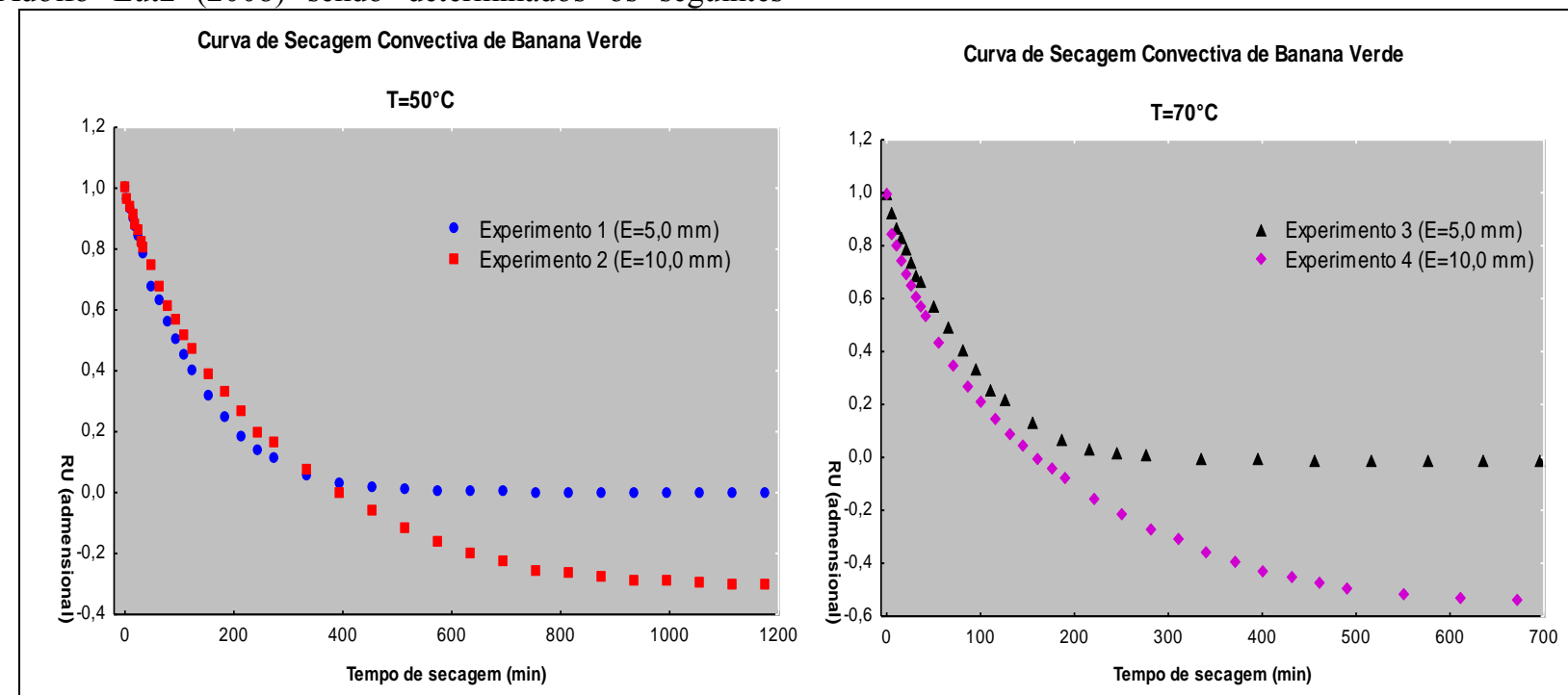
Figura 2. Curva de secagem da banana verde Pacovan para diferentes espessuras

Na Figura 2 verifica-se que nos experimentos onde as espessuras eram menores (experimentos 1 e 3 ), o processo de secagem ocorrido inicialmente foi o período de velocidade constante; enquanto que nos experimentos de maiores espessuras (experimentos 2 e 4) o processo de secagem ocorrido foi o período de velocidade decrescente, ou seja, a taxa de secagem aumenta com a diminuição da espessura, portanto o tempo de secagem foi diferente para cada curva de secagem. Tal fato esta relacionado à resistência encontrada pela umidade ao migrar do interior para a superfície das amostras.

A perda de umidade do material foi mais rápida no início do processo de secagem, em 120 minutos à temperatura de $50^{\circ} \mathrm{C}$ a razão de umidade foi de 0,50 enquanto que na temperatura de $70^{\circ} \mathrm{C}$ foi de 0,22 . O comportamento cinético, com relação ao estudo das temperaturas envolvidas no processo de secagem, pode ser observado na Figura 3.

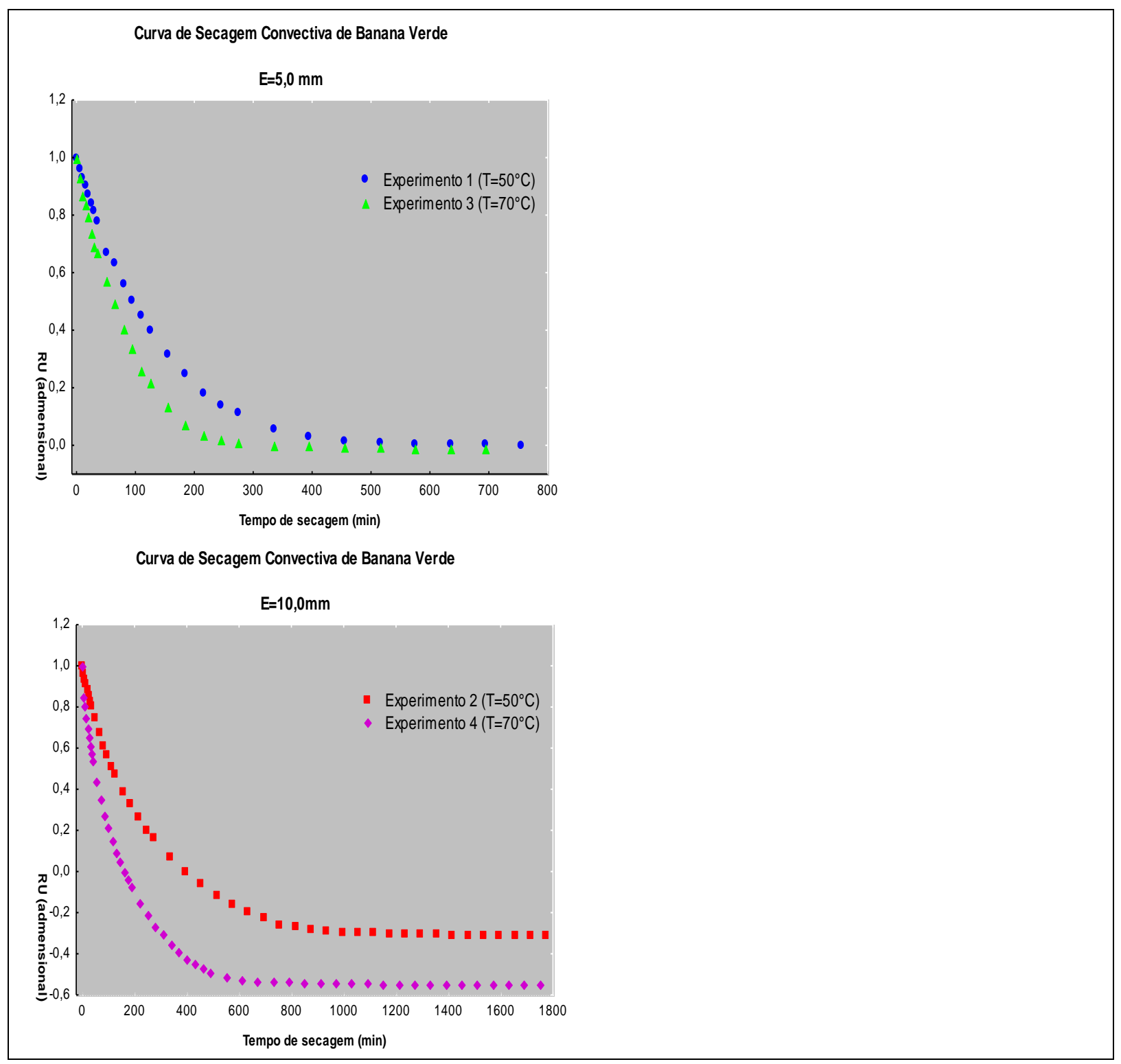

Figura 3. Curva de secagem da banana verde Pacovan para diferentes temperaturas 
Através das curvas de secagem, pode-se observar a influência da temperatura neste processo. Verifica-se que, para um mesmo tempo, quanto maior for à temperatura do ar, maior é a taxa de secagem e que a perda do conteúdo de umidade é mais rápida no início do processo de secagem, tendendo a estabilização.
Análise dos ensaios de secagem através do planejamento experimental

Os resultados obtidos para a temperatura e espessura, tendo como respostas o teor de umidade final em base seca e o tempo de secagem, estão apresentados na Tabela 3.

Tabela 3. Planejamento fatorial com matriz das variáveis independentes e variável resposta para os ensaios de secagem

\begin{tabular}{|c|c|c|c|c|c|}
\hline \multirow{2}{*}{ Ensaios } & \multicolumn{2}{|c|}{ Temperatura $(\mathrm{T})$} & \multicolumn{2}{|c|}{ Espessura (E) } & \multirow{2}{*}{$\begin{array}{c}\mathrm{U}_{\text {final }}(\text { b.s. }) \\
\%\end{array}$} \\
\hline & Codificada & $\operatorname{Real}\left({ }^{\circ} \mathrm{C}\right)$ & Codificada & Real (mm) & \\
\hline 1 & - & 50 & - & 5,0 & 7,57 \\
\hline 2 & + & 70 & - & 5,0 & 3,82 \\
\hline 3 & - & 50 & + & 10,0 & 7,01 \\
\hline 4 & + & 70 & + & 10,0 & 2,89 \\
\hline 5 & 0 & 60 & 0 & 7,5 & 5,89 \\
\hline 6 & 0 & 60 & 0 & 7,5 & 5,66 \\
\hline 7 & 0 & 60 & 0 & 7,5 & 5,22 \\
\hline
\end{tabular}

\section{Análise dos efeitos}

A Tabela 4 apresenta os efeitos principais e de interação das variáveis independentes, tendo como resposta à umidade em base seca para um modelo quadrático, considerando as interações entre as variáveis com um limite de confiança de $95 \%$. Os dados foram obtidos considerando o erro puro.

Tabela 4. Efeitos estimados do planejamento fatorial $2^{2}+3$ pontos centrais

\begin{tabular}{|c|c|c|c|c|c|}
\hline \multicolumn{6}{|c|}{ Efeitos Estimados: $\mathrm{R}^{2}=0,97842$} \\
\hline \multicolumn{6}{|c|}{ MS Erro Puro = 0,1159 } \\
\hline & \multicolumn{2}{|c|}{ Desvio Padrão } & \multirow[t]{2}{*}{$\mathrm{t}(2)$} & \multirow[t]{2}{*}{$\mathrm{P}$} & \multirow[t]{2}{*}{ Limite de Confiança 95\% } \\
\hline & Efeito & Erro Puro & & & \\
\hline Média/Interação & 5,43714 & 0,128675 & 42,2550 & 0,000560 & $(5,99078 ; 4,88350)$ \\
\hline Temperatura (T) & $-3,93500$ & 0,340441 & $-11,5585$ & 0,007402 & $(-2,47020 ;-5,39980)$ \\
\hline Espessura (E) & $-0,74500$ & 0,340441 & $-2,1883$ & 0,160120 & $(0,71980 ;-2,20980)$ \\
\hline $\mathrm{T}$ e $\mathrm{E}$ & $-0,18500$ & 0,340441 & $-0,5434$ & 0,641317 & $(1,27980 ;-1,64980)$ \\
\hline
\end{tabular}

Observa-se na Tabela 4 que o valor do coeficiente de determinação $\mathrm{R}^{2}$ foi de aproximadamente 98\%, indicando que um modelo quadrático representa bem a relação entre os efeitos e as resposta. Entretanto, para se conhecer se o modelo quadrático proposto possui significância estatística, deve-se fazer uma análise de variância (ANOVA).

As Tabelas 5 e 6 remetem a síntese dos resultados da análise de regressão para as respostas avaliadas estatisticamente, o percentual do teor de água de equilíbrio 
em base seca e o tempo de equilíbrio em horas, respectivamente.

Tabela 5. Resultados da análise de variância para o percentual do teor de água de equilíbrio em base seca

$\begin{array}{cccc}\text { Soma } & \text { Grau de } & \text { Média } & \text { Teste F } \\ \text { Quadrática } & \text { Liberdade } & \text { Quadrática } & \end{array}$

\begin{tabular}{ccccc}
\hline Regressão & 16,073 & 3 & 5,360 & \multirow{2}{*}{45,7} \\
\cline { 1 - 3 } Resíduo & 0,354 & 3 & 0,118 & \\
\hline Falta de Ajuste & 0,122 & 1 & 0,123 & \\
\hline Erro puro & 0,231 & 2 & 0.116 & \\
\hline Total & 16,428 & 6 & & \\
\hline $\mathrm{R}^{2}(\%)$ & 0,978 & & 9,280 \\
\hline $\mathrm{F}_{\text {tab } 0,95,3,3}$ & & & 4,92 \\
\hline $\mathrm{F}_{\text {calc }} / \mathrm{F}_{\text {tab }}$ & & & \\
\hline
\end{tabular}

Tabela 6. Resultados da análise de variância para o tempo de equilíbrio

\begin{tabular}{ccccc}
\hline & Soma Quadrática & $\begin{array}{c}\text { Grau de } \\
\text { Liberdade }\end{array}$ & $\begin{array}{c}\text { Média } \\
\text { Quadrática }\end{array}$ & Teste F \\
\cline { 1 - 2 } Regressão & 246,750 & 3 & 82,250 & \multirow{2}{*}{9,15} \\
\hline Resíduo & 26,964 & 3 & 8,990 & 78,9 \\
\hline Falta de Ajuste & 26,297 & 1 & 26,298 & \\
\hline Erro puro & 0,667 & 2 & 0,333 & \\
\hline Total & 273,714 & 6 & & 9,280 \\
\hline $\mathrm{R}^{2}(\%)$ & 0,900 & & 0,98 \\
\hline $\mathrm{F}_{\text {tab } 0,95,3,3}$ & & & \\
\hline $\mathrm{F}_{\text {calc }} / \mathrm{F}_{\text {tab }}$ & & & \\
\hline
\end{tabular}

A comparação entre os valores de $\mathrm{F}$, calculados e tabelados, indica que as respostas são estatisticamente significativas ao nível de $95 \%$ de confiança. Verifica-se então, que o coeficiente de determinação $\left(R^{2}\right)$ foi um pouco maior para a resposta teor de água final quando comparado com o do tempo de secagem. Os gráficos das superfícies de respostas são ferramentas importantes na analise das faixas ótimas de operação das variáveis de entrada. A Figura 4 mostra a superfície de resposta dos efeitos das variáveis temperatura $\left({ }^{\circ} \mathrm{C}\right)$ e espessura $(\mathrm{mm})$ sobre o tempo de equilíbrio de secagem em horas. 


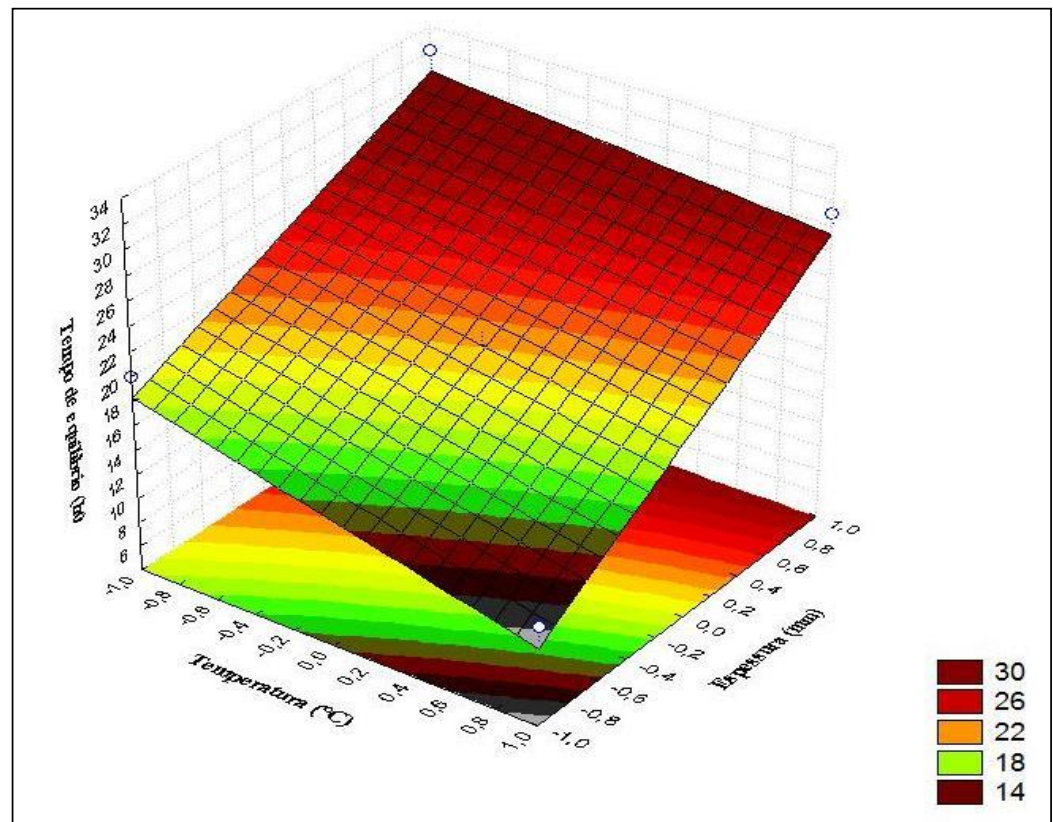

Figura 4. Tempo de equilíbrio de secagem em função da temperatura e espessura para a banana verde Pacovan

Observa-se nesta figura que diminuindo-se a espessura da camada na secagem, principalmente em espessuras fixada em 5,0 $\mathrm{mm}$ e em temperatura mais alta, $70^{0} \mathrm{C}$, obtém-se menores tempos de equilíbrio na secagem.

\section{Caracterização da polpa de banana verde}

Os resultados das análises na polpa da banana verde encontram-se representados na Tabela 7 , onde a acidez titulável está expressa em ácido málico e os carboidratos foram calculados pela diferença do somatório dos demais componentes.

Tabela 7. Caracterização da polpa de banana verde Pacovan

Parâmetros
Média dos valores \pm desvio padrão

\begin{tabular}{cc}
\hline $\mathrm{pH}$ & $3,81 \pm 0,08$ \\
\hline Acidez Titulável & $0,15 \pm 0,003$ \\
\hline SST $\left({ }^{\circ}\right.$ Brix $)$ & $2,20 \pm 0,05$ \\
\hline Umidade & $70,33 \pm 0,59$ \\
\hline Cinzas & $0,59 \pm 0,02$ \\
\hline Lipídeos & $0,32 \pm 0,20$ \\
\hline Proteínas & $1,45 \pm 0,16$ \\
\hline Fibra Bruta & $2,40 \pm 0,06$ \\
\hline Carboidratos Totais & 24,91 \\
\hline
\end{tabular}

Valores obtidos em triplicata.

A composição química da polpa de banana verde demonstra que os teores de cinzas $(0,6 \%)$ e fibras $(2,4 \%)$ pouco diferiram daqueles informados pela Tabela de Composição de Alimentos (TACO) de 0,7\% e 2,0\%.
Entretanto os teores de lipídeos $(0,32 \%)$, proteínas $(1,45 \%)$ e o teor de umidade inicial $(70,3 \%)$ encontraramse superiores aos encontrados aos dois primeiros parâmetros $(0,1 \%)$ e $(1,2 \%)$, mas inferior ao último de 
(77,7\%), ainda segundo a TACO (2011).

\section{Caracterização da farinha de banana verde (FBV)}

Para as determinações dos rendimentos dos sete ensaios de secagem foram retiradas $400 \mathrm{~g}$ de banana desidratada, na forma de rodelas, conforme os experimentos do planejamento fatorial (Tabela 3). Os resultados obtidos encontram-se na Tabela 8 .

Tabela 8. Rendimento dos diferentes ensaios de secagem para a obtenção da FBV

\begin{tabular}{ccc} 
Experimentos & Quantidade $(\mathrm{g})$ & Rendimento (\%) \\
\hline 1 & 52,40 & 13,10 \\
\hline 2 & 40,44 & 10,11 \\
\hline 3 & 117,16 & 29,29 \\
\hline 4 & 109,28 & 27,32 \\
\hline 5 & 81,20 & 20,30 \\
\hline 6 & 76,40 & 19,10 \\
\hline 7 & 75,32 & 18,83
\end{tabular}

Os experimentos 1 e 2 apresentaram os menores rendimentos devido as condições que se apresentaram: gomoso e borrachudo, sendo de difícil trituração e peneiramento. Entretanto, nos demais experimentos as amostras apresentaram-se duras e quebradiças, possibilitando maior eficiência na trituração e maior rendimento de peneiramento; onde o experimento 3 foi selecionado como o melhor.

A Figura 5 mostra a superfície de resposta do rendimento da FBV em função da temperatura e espessura. 


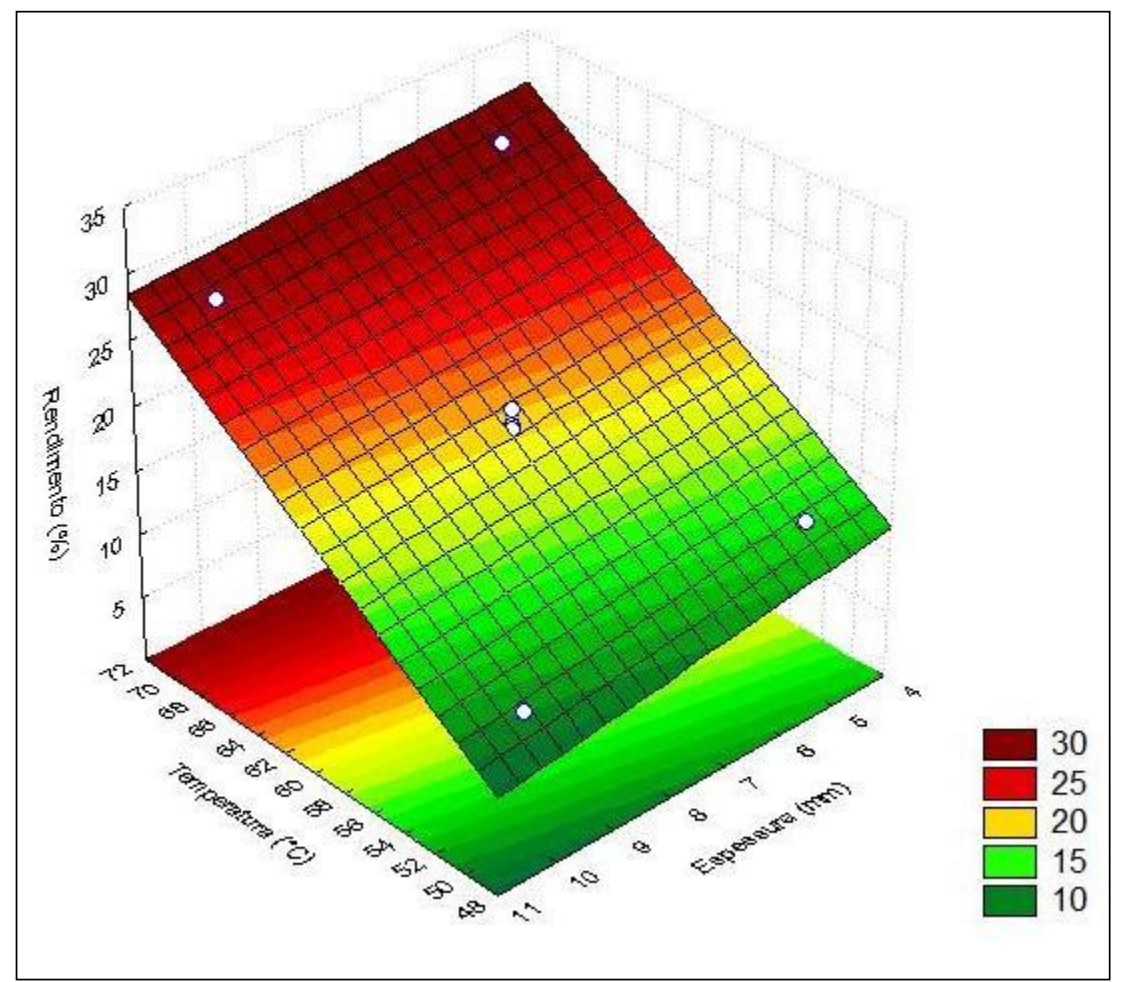

Figura 5. Rendimento da FBV em função da temperatura e espessura

Quando se opera o processo com o menor nível de espessura $(+1)$ e temperatura acima do ponto central, obtém-se a região, em vermelho escuro, que apresenta o maior valor de rendimento de farinha. A farinha de banana verde apresentou coloração bege claro, insípida e inodora.

Foram utilizados $3,592 \mathrm{~kg}$ de banana verde Pacovan sem a casca, a partir dos quais foram obtidos $1,052 \mathrm{~kg}$ de farinha, o que corresponde a um rendimento de $29,29 \%$. Na caracterização da FBV o valor médio de $\mathrm{pH}$ registrado foi de 3,82 e o da acidez titulável foi $0,58 \%$, sendo este último inferior, mas próximo, ao obtido por Borges et al. (2009) de 0,63\%. O valor médio dos sólidos solúveis foi de $8,35{ }^{\circ}$ Brix, evidenciando o estágio de maturação do fruto (verde). A Tabela 9 apresenta a composição centesimal da farinha obtida.

Tabela 9. Composição centesimal da FBV

\begin{tabular}{cc}
\hline $\begin{array}{c}\text { Componentes } \\
\text { Centesimais (\%) }\end{array}$ & $\begin{array}{c}\text { FBV } \\
\text { desvio padrão }\end{array}$ \\
\hline Umidade & $11,4 \pm 0,35$ \\
\hline Cinzas & $2,17 \pm 0,15$ \\
\hline Lipídeos & $0,58 \pm 0,13$ \\
\hline Proteínas & $0,45 \pm 0,27$ \\
\hline Fibra Bruta & $1,04 \pm 0,06$ \\
\hline Carboidratos Totais & 84,36 \\
\hline
\end{tabular}

Valores obtidos em triplicata.

O teor de umidade $(11,4 \%)$ encontra-se dentro do de no máximo de $14 \%$ em farinhas. Este valor apresentou- 
se superior ao encontrado por Fasolin et al. (2007), que obtiveram 7,55\% de umidade com a farinha de banana verde. Quanto às cinzas, o valor encontrado $(2,17 \%)$ é próximo ao encontrado por Torres et al. (2005) 2,00\% para a FBV da Nanicão.

Em relação ao teor de lipídeos, a farinha apresentou um teor igual a $0,58 \%$, valor um pouco superior ao encontrado por Torres et al. (2005), que constataram 0,53\%. Entretanto, Medeiros et al. (2010) encontraram para a FBV um valor de $0,88 \%$ e Borges et al. (2009) encontraram teor de $0,68 \%$; sendo estes superiores ao encontrado neste estudo. O teor de fibra bruta de 1,04\% está de acordo com a faixa de valores reportada por Borges et al. (2009) de 1,01 a 1,17\%.

\section{CONCLUSÕES}

A temperatura é o principal fator que afeta o processo de secagem e a taxa de secagem aumenta com a diminuição da espessura da banana; Os dados experimentais, ajustados aos modelos de Page e Henderson \& Pabis, representaram bem o processo de secagem para cinco dos sete experimentos realizados. As respostas (teor de água final e tempo de secagem) foram estatisticamente significativas ao nível de $95 \%$ de confiança. Para espessura fixada em $5,0 \mathrm{~mm}$ e temperatura a $70{ }^{\circ} \mathrm{C}$ obtém-se os menores tempos de equilíbrio na secagem; A farinha de banana verde apresentou textura fina, coloração bege claro, insípida e inodora.

A técnica de secagem convectiva é viável para a banana verde, cultivar Pacovan, e a farinha de banana verde obtida pode ser utilizada no enriquecimento e diversificação de produtos alimentícios.

\section{REFERÊNCIAS}

IAL. INSTITUTO ADOLFO LUTZ. Métodos físicoquímicos para análise de alimentos. Coordenadores Odair Zenebon, Neus Sadocco Pascuet e Paulo Tiglea São Paulo: Instituto Adolfo Lutz, 2008. p.1020.

ANVISA. AGÊNCIA NACIONAL DE VIGILÂNCIA SANITÁRIA. Resolução - RDC $\mathbf{n}^{\circ} \mathbf{2 6 3}$, de 17 de outubro de 2005. Regulamento técnico para produtos de cereais, amidos, farinhas e farelos. Disponível em: http://www.anvisa.gov.br/leisref/public/showact.php.

Acesso em 15 de janeiro de 2012.

BORGES, A. M. PEREIRA, J. LUCENA, E. M. P. Caracterização da farinha de banana verde. Ciência e Tecnologia de Alimentos, v. 29, n. 2, p. 333-339, abr/jun, 2009.

FASOLIN, L. H.; ALMEIDA, G. C.; CASTANHO, P. S.; NETTO-OLIVEIRA, E. R. Biscoitos produzidos com farinha de banana: avaliação química, física $e$ sensorial. Ciência e Tecnologia de Alimentos. Campinas, v. 27, n.3, p. $524-529,2007$.

GARRUTI, D. S. et al. Aceitação de cultivares de bananas resistentes à Sigatoka Negra junto ao consumidor da região Nordeste do Brasil. Ciência Rural, v. 42, n. $5,2012$.

HENDERSON, S. M.; PABIS, S. Grain drying theory I. Temperature effect on drying coefficient. Journal of Agriculture Engineering Research, v.6, n.3, p.169-174, 1961.

IBGE. Instituto Brasileiro de Geografia e Estatística. Tabela da Produção Agrícola 2011. Disponível em http://www.cnpmf.embrapa.br/planilhas/Banana_Brasil_2 011.pdf. Acesso em 22/06/2013.

MEDEIROS, M. J. OLIVEIRA, P. A. A. C. SOUZA, J. M. L. SILVA, R. F. SOUZA, M. L. Composição química de misturas de farinhas de banana verde com castanha-do-Brasil. Revista do Instituto Adolfo Lutz. São Paulo, v. 69, n. 3, p. 396-402, 2010.

PAGE, G. E. Factors influencing the maximum of air drying shelled corn in thin layer. Thesis dissertation (M.Sc.) - Purdue University, Indiana, 1949.

RAMOS, D. P.; LEONEL, M.; LEONEL, S. Amido resistente em farinhas de banana verde. Alimentos e Nutrição, Araraquara, v.20, n.3, p. 479-483, 2009.

SANTOS, I. B. et al. Transporte de massa em sólidos com forma arbitrária via método integral baseado em Galerkin usando condição de contorno convectiva. Mecánica Computacional. Buenos Aires, v. xxix, p. 2865-2881, 2010.

SANTOS, P. dos et al. Influência de pré-tratamentos na cinética de secagem em diferentes temperaturas de banana da variedade terra (Musa Sapientum, Linneo). Revista Brasileira de Tecnologia Agroindustrial, v. 4, n. 2, p. 218-234, 2010

SILVA, M. V., ROSA, C. I. L. F., VILAS BOAS, E. V. B. Conceitos e métodos de controle do escurecimento enzimático no processamento mínimo de frutas e hortaliças. Boletim CEPPA, Curitiba, v.27, n.1, p.83-96, 2009.

SOUZA, A. F.; LEÃO, M. F. Análises dos métodos mais eficientes na inibição do escurecimento enzimático em frutas e hortaliças. Enciclopédia Biosfera. Centro Científico Conhecer, Goiânia, v.8, n.15, 2012.

STATISTIC FOR WINDOWS 5.0. Computer Program Manual. Tulsa: StatSoft, Inc., 1995. 
TACO. Tabela Brasileira de Composição de Alimentos. 4. ed. rev. e ampl.. Campinas: NEPA UNICAMP, 2011. $161 \mathrm{p}$.

TORRES, L. L. G. et al. Efeito da umidade e da temperatura no processamento de farinha de banana verde (Musa acuminata, grupo AAA) por extrusão termoplástica. Boletim do Centro de Pesquisa de Processamento de Alimentos. Curitiba, v. 23, n 2, p. 273-290, jul./dez. 2005. 